\title{
Evaluation of Severity in Patients of Acne Vulgaris by Global Acne Grading System in Bangladesh
}

\author{
Zohra FT11, Sultana ${ }^{2 *}$, Islam $\mathrm{S}^{1}$ and Nasreen $\mathrm{T}^{1}$ \\ 1Department of Clinical Pathology, Bangabandhu Sheikh Mujib Medical University, \\ Shahbag, Dhaka \\ ${ }^{2}$ Professor of Clinical Pathology, Bangabandhu Sheikh Mujib Medical University, \\ Shahbag, Dhaka
}

Research Article

Volume 1 Issue 1

Received Date: May 16, 2017

Published Date: June 15, 2017

DOI: $10.23880 /$ cprj-16000105

*Corresponding author: Tuhin Sultana, Department of Clinical Pathology, Bangabandhu Sheikh Mujib Medical University, Shahbag, Dhaka, Bangladesh, E-mail: drtsultana@gmail.com

\section{Abstract}

Background: Because of its polymorphic and dynamic nature, acne vulgaris is notably difficult to evaluate objectively, and this hampers the assessment of new treatment methods or new drug effects.

Objective: We sought to evaluate an overall impression of the country regarding severity of acne vulgaris.

Methods: This cross sectional study was carried out at the Department of Laboratory Medicine in collaboration with the Department of Dermatology\& Venereology, BSMMU, Dhaka. In this study total 48 patients of acne vulgaris were investigated who attended in the outpatient Department of Dermatology\& Venereology, BSMMU. Detail information regarding acne vulgaris were collected by a data collection sheet.

Result: All patients were assessed according to GAGS and grouped as mild, moderate, severe and very severe. In this study, 48 cases of acne vulgaris were enrolled. The mean age was found $22.1 \pm 6.5$. It was observed that almost two third $(62.5 \%)$ patients were female and $18(37.5 \%)$ patients were male. $29.17 \%$ patients had mild acne vulgaris, majority $41.6 \%$ were moderate, $16.7 \%$ were severe and $12.5 \%$ were very severe according to GAGS.

Conclusion: This was a study on a limited number of cases. There is a great need of epidemiological studies with sufficient follow-up.

Keywords: Acne Vulgaris; Acne Severity; Global Acne Grading System

\section{Introduction}

The term acne is derived from Greek word "acme" which is used in the sense of skin eruption and vulgaris indicate the meaning "common" [1]. It is the eighth most prevalent disease worldwide. It is estimated that $9.4 \%$ of the global population are affected by acne vulgaris [2].
Nearly 80 percent of population presents episodes of acne between the ages of 11 to 30 years [3]. The estimation of the prevalence of acne vulgaris in adolescent ranges from 30 to 90 percent [4]. 
Acne vulgaris is a common chronic inflammatory disease of the pilosebaceous unit which is characterized by the formation of non-inflammatory open and closed comedones \& inflammatory papules, pustules, nodules and cysts [5]. Acne vulgaris occurs on areas of the body with large sebaceous glands, including the face, cheek, nose, and forehead \& also on the chest, upper back \& upper arms [6]. Although, acne does not cause any serious health threat with self-limiting condition, it may cause significant psychological and social problems, depression, low self-esteem, disfigurement and scarring that can persist for a lifetime [7].

The precise mechanisms of acne are not known but there are four major pathophysiologic factors including excessive sebum production, follicular hyper keratinization and proliferation of Propioni bacterium acnes with direct or indirect inflammation. Although easy to diagnose, the polymorphic nature of acne vulgaris and its varied extent of involvement do not permit simple evaluation of its severity. In general, laboratory workup is not indicated for patients with acne. Secondary causes and suspected underlying endocrine disease or virilisation should be investigated [8].

Acne lesions may vary in number during the natural course of the disease and multiple measurements have been developed which is based on clinical examination and photographic documentation, to measure the clinical severity [9]. The Grading of acne based on the type of lesions, affected surface area and their severity that can help in deciding which therapies are needed in each individual. However, no grading system has been accepted universally [10]. The Global Acne Grading System (GAGS) was first developed by Doshi and Colleagues which is a quantitative scoring system to assess the severity of acne. According to this score acne was graded as mild, moderate, severe and very severe [11].

\section{Materials and Methods}

Study design, place and period: This cross sectional study was carried in the Department of Laboratory Medicine, BSMMU, collaboration with the Department of Dermatology \& Venereology, BSMMU, Dhaka during March 2016 to February 2017.

\section{Study Population}

Patients attended in the Dermatology and Venereology Department of BSMMU was enrolled in this study.

\section{Selection of Cases}

Inclusion Criteria: Patients of acne vulgaris from 11-35 years of age and irrespective of sex those attended in the outpatient Department of Dermatology and Venereology, BSMMU were enrolled in this study.

Exclusion Criteria: Patients having history of Pregnancy and Lactation, History of corticosteroids, oral contraceptive pills and iron intake, suffering from active malignancy or any cosmetic induced acne were excluded from this study.

Study Procedure: In this study, total 48 acne vulgaris patients were enrolled by consecutive sampling. Thereafter, appropriate subjects were chosen by selection criteria. Informed written consent was taken from the study subject. The patients were then be categorized into 4 groups according to acne severity by Global Acne Grading System.

\section{Global Acne Grading System (GAGS)}

The GAGS is a quantitative scoring system to assess acne severity. It was first developed by Doshi and colleagues in 1997. The total severity score is derived from summation of six regional sub scores. Each is derived by multiplying the factors- 2 for forehead, 2 for each check, 1 for nose, 1 for chin, 3 for both chest and back by the most heavily weighted lesion within each region ( 1 for $\geq$ one comedone, 2 for $\geq$ one papule, 3 for $\geq$ one pustule, and 4 for $\geq$ one nodule). The regional factors were derived from consideration of surface area and distribution and density of pilosebaceous units [1] (Table 1).

\begin{tabular}{|c|c|c|}
\hline Location & \multicolumn{2}{|c|}{$\begin{array}{c}\text { Factor X Grade (0-4) = local } \\
\text { score }\end{array}$} \\
\cline { 1 - 2 } Forehead & 2 & [Global score $=$ \\
$0=$ None \\
$1-18=$ Mild \\
$19-30=$ \\
Right cheek & 2 & Moderate \\
\cline { 1 - 2 } Left cheek & 2 & $31-38=$ Severe \\
\cline { 1 - 2 } Nose & 1 & $39=$ Very \\
\cline { 1 - 1 } Chin & 1 & severe] \\
\hline Chest \& upper back & 3 &
\end{tabular}

Grade 0 , No lesions; $1 \geq$ One comedone; $2 \geq$ One papule; 3 $\geq$ One pustule; $4 \geq$ One nodule

Table 1: The Global Acne Grading System.

\section{Data Collection and Processing}

Data was collected by a pre designed pro forma. Patient information was obtained through using patient's 
information sheet which involve questionnaire and clinical finding.

\section{Statistical Analysis}

Data were processed and analyzed by using computer software SPSS 20 (Statistical package for social sciences version 20 by applying appropriate formula). Mild, moderate, severe and very severe acne were determined and expressed as mean \pm SD.

\section{Ethical Consideration}

Prior to the commencement of this study, it was approved by the Ethical Institutional Review Board (IRB) of BSMMU, Dhaka.

\section{Results}

In this study, total 48 acne patients were divided into four groups as mild, moderate, severe and very severe acne. This severity was classified according to GAGS which is a quantitative scoring system. It was observed that almost half of the patients belonged to age 11-20 years (Table 2) (Figure 1). The mean age was found $22.1 \pm$ 6.5 years with ranged from 11 to 35 years. Gender differences in acne vulgaris were also significant (Table $3)$. There was clear female predominance in the present study. Males were $37.5 \%$ and females were $62.5 \%$. Among 48 patients, 18 patients were male and 30 patients were female. In present study, it was observed that $29.17 \%$ patients had mild acne vulgaris, majority $41.6 \%$ were moderate, $16.7 \%$ were severe and $12.5 \%$ were very severe according to GAGS.

\begin{tabular}{|c|c|c|}
\hline Age (in years) & Number of patients & Percentage \\
\hline $11-20$ & 23 & 47.9 \\
\hline $21-30$ & 21 & 43.8 \\
\hline $31-40$ & 4 & 8.3 \\
\hline Mean \pm SD & 22.1 & \pm 6.5 \\
\hline Range (min, max) & 11 & -35 \\
\hline
\end{tabular}

Table 2: Distribution of the study patients by age $(n=48)$.

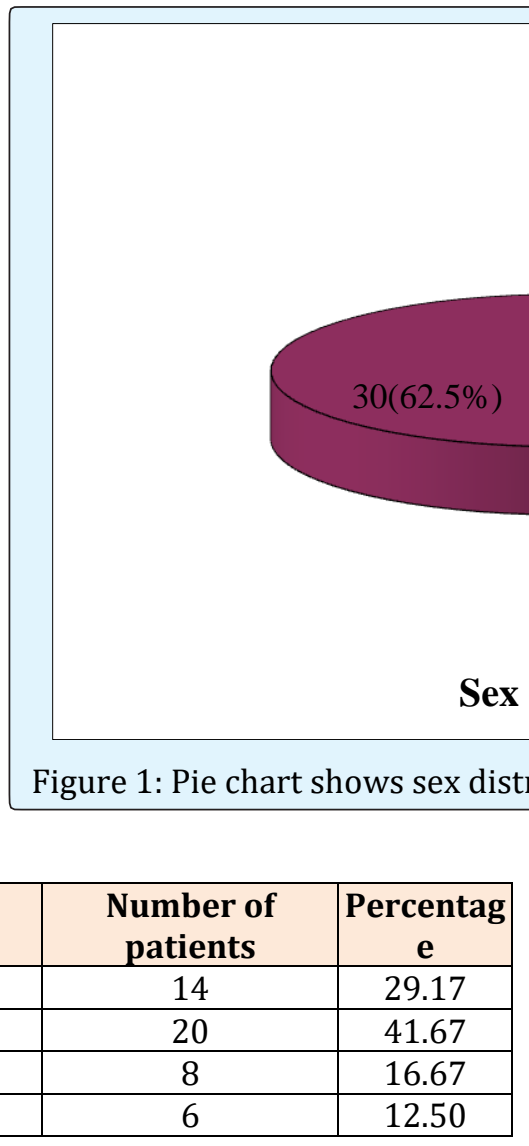

Table 3: Distribution of the study patients by Severity of acne vulgaris $(n=48)$.

\section{Discussion}

Recent general and institutional studies have shown that the prevalence of acne is broadly consistent globally, ranking it as the eighth most prevalent disease worldwide [2]. It is the most common cutaneous disorder affecting adolescents and young adults [3]. Although excessive sebum production, follicular hyper keratinization, Propioni bacterium acnes colonization and inflammation 
are found to be responsible in the pathogenesis of acne, the exact mechanisms are unknown [8].

This cross sectional study was done on Department of Laboratory Medicine in collaboration with the Department of Dermatology \& Venereology, BSMMU and Department of Biochemistry \& Molecular Biology, University of Dhaka. In this study, acne patient were divided into four groups as mild, moderate, severe and very severe acne. This severity was classified according to GAGS which is a quantitative scoring system.

Several systems for grading the severity of acne exist. It is useful for the initial evaluation and management of acne, to aid in the selection of appropriate therapeutic agents and to evaluate the treatment response [10].

"The acne lesion-counting technique" divides the face into five regions. In each region, the number of open and closed comedones, papules, pustules, and nodules are counted. Global assessment is a five-grade classification of acne into the categories of very mild, mild, moderate, severe, or very severe, based on a rater's overall impression. Comedonal acne is viewed as mild, papulopustular acne is moderate, and nodular acne is severe. The Plewig and Kligman system divides acne into three sub-types, namely comedonal, papulopustular, and conglobate. The right side of the face is considered, and severity of disease is assessed on I-IV scale according to the number of lesions and the predominant lesion type that is inflammatory or non-inflammatory [12]. The Cunliffe score or Leeds technique is a photonumeric grading scale. Grading involves comparing the patient's severity of acne to a standard photographic manual and assigning a score from mild to very severe [13]. Cook's photographic method uses a zero to eight severity scale based on photographic standards [12]. Allen and Smith's classification uses Cook's grading scale as well as lesion counting. Comedones and papules are counted on the right side of the face, while pustules and overall severity grading are evaluated on both sides of the face [14]. Fluorescence photography assesses the severity of comedonal acne. A zero to three scale assigning fluorescence grades of none, mild, moderate and extensive is used [15].

The Global Acne Grading System (GAGS) is an attempt to incorporate the advantages of the more elaborate acne grading systems listed above, while retaining simplicity. This system considers six locations on the face, chest and back with a factor for each locations based on surface area, distribution and density of pilosebaceous units [11].

\section{Conclusion}

To get an overall impression of the country regarding acne vulgaris, more integrated study is needed. Further study must include economical support and multi centered prospective cohort study with large sample size could be ensured.

\section{References}

1. Pokharel G, Harish B (2014) Acne Vulgaris: knowledge and attitude among Nepali school students. International Journal of Nursing Research and Practice 1(1): 29-33.

2. Tan JK, Bhate K (2015) A global perspective on the epidemiology of acne. Br J Dermatol 172(1): 3-12.

3. Mogaddam RM, Ardabilli NS, Maleki N, Soflaee M (2014) Correlation between the Severity and Type of Acne Lesions with Serum Zinc Levels in Patients with Acne Vulgaris. Biomed Res Int 474108.

4. Collier CN, Harper JC, Cantrell WC, Wang W, Foster KW, et al. (2008) The prevalence of acne in adults 20 years and older. J Am Acad Dermat 58(1): 56-59.

5. Tahir CH (2010) Pathogenesis of acne vulgaris: simplified. Journal of Pakistan Association of Dermatologists 20(2): 93-97.

6. Jeremy AHT, Holland DB, Roberts SG, Thomson KF, Cunliffe WJ (2003) Inflammatory events are involved in acne lesion initiation. J Invest Dermatol 121(1): 2027.

7. Pruthi GK, Babu N (2000) Physical and psychosocial impact of acne in adult female. Indian J Dermatol 57(1): 26-29.

8. Ibbotson SH, Dawe RS (2014) Skin disease. In: Walker B, et al. (Eds.) Davidson's Principles \& Practice of Medicine 22 ${ }^{\text {nd }}(E d n$.$) , Churchill Livingstone Elsevier,$ Edinburgh, pp: 1281-1282.

9. Witkowski JA, Parish LC (2004) The assessment of acne: An evaluation of grading and lesion counting in the measurement of acne. Clin Dermatol 22(5): 394397.

10. Strauss JS, Daniel PK, Leyden JJ, Lucky AW, Shalita AR, et al. (2007) Guidelines of care for acne vulgaris management. J Am Acad Dermatol 56(4): 651-663. 
11. Doshi A, Zaheer A, Stiller MJ (1997) A comparison of current acne grading systems and proposal of a novel system. Int J Dermato 36(6): 416-418.

12. Witkowski JA, Paris LC, Guin JD (1980) Acne grading methods. Arch Dermatol 116(5): 517-518.

13. Burke BM, Cunliffe WJ (1984) The assessment of acne vulgaris-the Leeds technique. Br J Dermatol 111(1): 83-92.
14. Allen BS, Smith JG (1982) Various parameters for grading acne vulgaris. Arch dermatol 118(1): 23-25.

15. Gibson JR, Harvey SG, Barth J, Darley CR, Reshad H (1984) Assessing inflammatory acne vulgaris-correlation between clinical and photographic methods. Br J Dermatol 111(27): 168-170. 